\title{
ATUALIZAÇÃO
}

\section{Aula expositiva}

\section{RESUMO}

A aula expositiva tem sido apontada como técnica que transforma o aluno em mero expectador do processo ensino-aprendizagem. 0 autor procura mostrar que a exposição oral, planejada adequadamente, considerando a maneira de o aluno assimilar, organizar $e$ utilizar a informação, inclui-se entre as técnicas que se recomendam para o ensino superior.

A sociedade contemporânea vem sofrendo profundas transformações que se refletem no sistema escolar, exigindo sua reformulação.

$O$ ensino na universidade moderna torna-se tarefa extremamente complexa, defrontando-se com problemas decorrentes de necessidades econômicas, técnicas e científicas da sociedade, do aumento do número de alunos e da carência de pessoal docente qualificado.

$O$ docente universitário, que em sua maioria selecionava as atividades em classe orientando-se mais pela tradição do que por tomada de decisão entre opções analisadas criteriosamente, vem desenvolvendo uma atitude científica, mais analítica, para com o ensino. Há uma crescente conscientização da necessidade de preparo para o magistério, não só quanto ao domínio do conteúdo das disciplinas, mas também em relação às teorias de aprendizagem $\mathrm{e}$ suas implicações no ensino.

* Assessora Pedagógica da ABEM.
Riva Roitman*

Apesar de não haver consenso entre as teorias da aprendizagem quanto à maneira como o indivíduo aprende, os conceitos e princípios das várias teorias podem auxiliar o professor a tomar decisões sobre sua atuação na sala de aula. Ao decidir diante da diversidade de opções que se lhe apresentam, o professor não deve esquecer que o processo didático implica a existência de um fim a ser alcançado mediante a relação professor-aluno.

Estratégias diversificadas, fundamentadas em diferentes teorias, podem ser desenvolvidas, não obstante a interferência das inúmeras variáveis relacionadas ao processo ensino-aprendizagem. Essas variáveis, ligadas, por exemplo, ao aluno, ao professor, ao conteúdo, aos objetivos, ao ambiente etc., podem dificultar, ou facilitar, a aplicação das teorias às situações de classe.

Uma entre as medidas que vêm sendo muito difundidas, visando a auxiliar o processo ensino-aprendizagem, é a renovação de técnicas. Apresentada, muitas vezes, como uma das soluções disponíveis, os resultados nem sempre são os esperados.

A ênfase na utilização e busca de novas técnicas levou ao questionamento e até mesmo à condenação da aula expositiva.

Originária do ensino nas universidades medievais, em que somente o professor tinha acesso ao texto, lendo-o para os alunos com comentários apropriados, sofreu nos últimos anos severas críticas e grande reação ao seu emprego, chegando a ser repudiada pelos professores "inovadores". 
Os movimentos e inovações educacionais das últimas décadas, enfatizando os programas de atividades individualizadas, diferentes maneiras de desenvolver experiências não-verbais na classe, os métodos de projeto e de resolução de problemas, contribuíram para a má interpretação do potencial da aula expositiva.

O que há de errado com a aula expositiva é ser ela utilizada sem a compreensão da complexidade envolvida na transmissão e recepção da informação.

A partir das teorias sobre o processamento da informação, desenvolvidas por psicólogos congnitivos, extrapola-se uma teoria de aprendizagem em que o aprendiz é visto como um ser ativo, que capta e seleciona estímulos do meio ambiente, organiza dados, detecta problemas, elabora conceitos, cria soluções para problemas, utiliza símbolos verbais e não-verbais. A linguagem destaca-se como fator importante no processamento da informação, sendo a comunicação interior do indivíduo uma interação entre estímulos do ambiente e símbolos para representá-los.

Ausubel ${ }^{1}$, psicólogo cognitivo e autor da teoria da aprendizagem significativa, defende a exposição verbal, argumentando que os pontos negativos que lhe são atribuídos não são inerentes à exposição, mas decorrem de sua má utilização. Dentre as falhas que a levaram ao descrédito, podem ser citadas: emprego das técnicas verbais para alunos de condição cognitiva imatura; apresentação de informações sem a organização hierárquica das idéias; falta de integração com conteúdos previamente apresentados; utilização de procedimentos de avaliação que medem apenas a capacidade de reconhecer fatos isolados e de reproduzir idéias com as mesmas palavras, ou em contexto idêntico ao original.

Bruner $^{2}$, outro psicólogo cognitivo, defensor da aprendizagem por descoberta, considera o aluno totalmente passivo durante a exposição, ao contrário da sua participação no processo de adquirir informações, formular hipóteses e avaliar a informação na aprendizagem por descoberta.
Segundo Ausubel, a aprendizagem por recepção verbal não é sempre mecânica, como diz Bruner, nem a aprendizagem por descoberta é sempre significativa. Tanto na prática em laboratório, como na resolução de problemas, se o aluno executar as experiências e resolver corretamente os problemas sem a compreensão dos conceitos e princípios envolvidos, a aprendizagem não será significativa, e sim mecânica.

Ausubel argumenta que a aprendizagem por solução de problemas e a compreensão do material verbal apresentado têm diferentes objetivos e que as condições e técnicas que facilitam um desses processos de aprendizagem não são necessariamente relevantes, ou eficientes, para outro.

Uma das críticas de maior repercussão feita à aula expositiva é a de contribuir para que o aluno adote uma atitude passiva diante da aprendizagem, ficando como mero receptor de informações. Isso se deve a que, na aprendizagem por recepção verbal, o aluno recebe a informação já em sua forma final, pronta para ser internalizada, ao contrário da aprendizagem por descoberta, que exige que o aluno descubra o conteúdo antes de internalizá-lo.

Entretanto; a atividade do aluno na aprendizagem por recepção verbal envolve mais que a simples catalogação dos conceitos que the são fornecidos - exige a compreensão de novos significados e a conseqüente integração na sua estrutura cognitiva, ou seja, no conjunto organizado de fatos, conceitos e generalizações que o indivíduo aprendeu. A aprendizagem por recepção verbal implica julgamento da relevância, para decidir sobre o novo conhecimento, e tradução para um referencial pessoal, consonante com a experiência anterior, com o vocabulário e com a estrutura de idéias. Posteriormente, alguma reorganização tornar-se-á necessária, sempre que houver discrepâncias, ou conflitos, entre o conhecimento novo adquirido e o já existente.

Embora a incorporação de idéias e conceitos na estrutura cognitiva do aprendiz não seja um fenômeno passivo, há a possibilidade de ocorrer a aprendizagem verbalista mecânica, isto é, 
a aprendizagem de respostas verbais por memorização. $\mathrm{Na}$ aprendizagem por recepção verbal, pode o aluno acreditar que compreendeu significados precisos, quando na realidade guardou um conjunto vago e confuso de generalidades sem significado real. A fim de evitar esse risco, a aula expositiva pode ser intercalada com exemplos, questões e problemas, facilitando variedades ativas de aprendizagem por recepção.

A aprendizagem significativa, isto é, a compreensão e integração da informação na estrutura cognitiva do aprendiz, terá maior possibilidade de ocorrer se houver, na aula expositiva, a preocupação de relacionar, de modo organizado, o conteúdo a ser aprendido com o que já é conhecido pelo aluno; de correlacionar os aspectos essenciais com experiências prévias do aluno.

A exposição também sofre críticas por ser considerada sinônimo de ensino dedutivo. Esta é uma afirmação muito difundida, embora a dedução não seja uma característica da exposição per si. A aula expositiva pode ser organizada segundo princípios dedutivos, ou indutivos.

A apresentação verbal pode partir da regra geral, para em seguida exemplificar, mostrar como esses exemplos pertencem ao caso geral, e explicar por que a regra funciona de determinada maneira. Neste caso, estaŕá seguindo os passos da dedução. Ao contrário, a mesma informação pode ser organizada de acordo com as operações lógicas da indução, partindo de exemplos selecionados, mostrando a possibilidade de generalização dos exemplos específicos e de outros, e concluindo com a formulação precisa da regra geral.

Embora não haja consenso entre os psicólogos cognitivos sobre a melhor teoria, nem concordância sobre um modelo que englobe todos os aspectos da atividade mental, podem ser aplicados à exposição princípios sobre o processamento de informações que é um modo altamente complexo de as transmitir e receber.

Já que o aprendiz é visto como um ser ativo que não apenas recebe, mas que processa $\mathrm{e}$ armazena a informação recebjda, a aula expositiva passa a ser planejada e executada levando- se em consideração o.que é conhecido sobre a maneira de o indivíduo assimilar, relacionar, organizar e acumular a informação. Há preocupação não só em apresentar informações, mas com a sua organização e utilização por parte dos alunos.

O propósito fundamental da aula expositiva é apresentar fatos, conceitos e generalizações por meio da ordenação verbal do professor. É mais adequada a alunos que tenham um repertório de conceitos e princípios básicos em uma área de conteúdo, o que acontece com estudantes universitários. Presta-se bem para introduzir conteúdo; clarificar aspectos difíceis de um tópico; propiciar uma visão geral do tema; destacar uma abordagem específica; fornecer informação à qual o aluno não tenha acesso.

Em geral, a aula expositiva segue a seguinte seqüência: apresentação do assunto a ser estudado; desenvolvimento analítico do tema; e síntese, conclusão, ou aplicação concretas.

A introdução presta-se a identificar pontos chaves, ou conceitos, que serão apresentados. É uma maneira de o aluno atentar para as informações que serão expostas, evitando sua dispersão, já que antes de processar a informação é necessário que o aluno preste atenção a ela. Da introdução poderão constar os objetivos específicos do encontro; o marco de referência que facilitará a compreensão do que será exposto (correlacionando com conteúdos já aprendidos); a importância do que será tratado na aula.

O desenvolvimento pode servir para ressaltar os aspectos principais e auxiliar a aprendizagem significativa através da correlação com conceitos familiares aos alunos. Segundo Lafourcade $^{3}$ :

"quando a exposição visa a elucidar um determinado problema, o desenvolvimento poderá incluir uma breve relação das principais investigações feitas e as conclusões mais importantes; a opinião de especialistas; as criticas aos trabalhos realizados; a própria versão sobre o problema $e$ a sugestão para resolvê-lo. Quando a exposição apresenta alguma explicação de um 
esquema conceitual de certa complexidade (teoria, ou modelo), o desenvolvimento poderá apresentar um diagrama indicando os componentes do esquema; apresentar a definição dos principais conceitos; a seleção dos fatos mais representativos que possibilitaram generalizações do esquema; os sistemas hipotético-dedutivos usados; a natureza de suas inferências e modos de validação; a comparação com outros esquemas conceituais".

Os auxílios visuais para clarificar e destacar conceitos podem ser usados, já que aula expositiva não é necessariamente sinônimo de exclusiva apresentação oral pelo professor.

$\mathrm{Na}$ conclusão podem ser revistos e enfatizados os aspectos mais importantes que foram apresentados. A introdução mostra os objetivos a alcançar; a conclusão permite a comparação entre os objetivos e os resultados.

A aula expositiva pode, pois, apesar de tradicional, ṁerecer ainda um lugar didático, desde que bem realizada.

Entre as vantagens de seu emprego podem ser citadas: estruturar logicamente o conteúdo da disciplina; sintetizar um assunto extenso; ressaltar os aspectos mais importantes; relatar experiências pessoais; condensar material de fontes variadas.

Como desvantagens, tem-se, entre outras, 0 fato de estar centrada na habilidade de comunicação do professor; depender de sua capacidade e domínio do conteúdo; dificultar oportunidades para que o aluno explore, pense e interaja, ou seja, dificultar a investigação, abstração e comunicação verbal.

Decidir se a aula expositiva é a melhor forma para o aluno aprender o tópico em questão depende dos objetivos, do número de alunos, das condições do ambiente e das características pessoais e intelectuais do professor e do aluno. Uma vez selecionada, precisam ser observados cuidados relacionados com a orga- nização e hierarquização do conteúdo, decorrentes da estrutura do material informativo, bem como os relacionados com a comunicação em si - clareza de linguagem, precisão, fluência verbal.

Apesar das críticas, a aula expositiva apresentou resultados positivos no passado, está sendo usada no presente, com várias modificações, e tudo indica que continuará a ser utilizada no futuro.

E como o pintor que utiliza tintas de diferentes matizes para a criação de um quadro, o professor poderá mesclar diferentes técnicas para facilitar e propiciar a aprendizagem de seus alunos.

\section{SUMMARY}

It has been pointed out that lectures turn students into mere observers in the learning process.

The author tries to show that lectures properly planned are still on of the most useful techniques in teaching at graduation level, taking into account the students' capacity to absorb, organize and use the information given.

\section{REFERENCIAS BIBLIOGRÁFICAS}

1. AUSUBEL, David P. - The Psychology of meaningful verbal learning. New York, Grune \& Stratton, 1963.

2. BRUNER, Jerome S. - The Relevance of Education. New York, Norton, 1971.

3. LAFOURCADE, Pedro D. - Planejamento, conducción y evaluación en la enseñanza superior. Buenos Aires, Kapelusz, 1974.

Endereço do autor:

ASSOCIACCÃO BRASILEIRA DE EDUCAÇÃO MÉDICA Rua Leopoldo Bulhőes, $1480-3^{\circ}$ andar

21041 - Manguinhos

Rio de Janeiro-RJ 